Article

\title{
Structuring Climate Adaptation through Multiple Perspectives: Framework and Case Study on Flood Risk Management
}

\author{
Mohanasundar Radhakrishnan 1,2, , Assela Pathirana 1,2, Richard Ashley ${ }^{1,2}$ and \\ Chris Zevenbergen ${ }^{1}$ \\ 1 UNESCO-IHE Institute for Water Education, 2611 AX Delft, The Netherlands; \\ a.pathirana@unesco-ihe.org (A.P.); r.ashley@sheffield.ac.uk (R.A.); c.zevenbergen@unesco-ihe.org (C.Z.) \\ 2 Cooperative Research Centre for Water Sensitive Cities, Clayton, Melbourne, VIC 3800, Australia \\ * Correspondence: m.radhakrishnan@unesco-ihe.org; Tel.: +31-(0)-152151715
}

Academic Editor: Athanasios Loukas

Received: 24 September 2016; Accepted: 4 February 2017; Published: 19 February 2017

\begin{abstract}
Adaptation to climate change is being addressed in many domains. This means that there are multiple perspectives on adaptation; often with differing visions resulting in disconnected responses and outcomes. Combining singular perspectives into coherent, combined perspectives that include multiple needs and visions can help to deepen the understanding of various aspects of adaptation and provide more effective responses. Such combinations of perspectives can help to increase the range and variety of adaptation measures available for implementation or avoid maladaptation compared with adaptations derived from a singular perspective. The objective of this paper is to present and demonstrate a framework for structuring the local adaptation responses using the inputs from multiple perspectives. The adaptation response framing has been done by: (i) contextualizing climate change adaptation needs; (ii) analyzing drivers of change; (iii) characterizing measures of adaptation; and (iv) establishing links between the measures with a particular emphasis on taking account of multiple perspectives. This framework was demonstrated with reference to the management of flood risks in a case study Can Tho, Vietnam. The results from the case study show that framing of adaptation responses from multiple perspectives can enhance the understanding of adaptation measures, thereby helping to bring about more flexible implementation practices.
\end{abstract}

Keywords: climate adaptation; flexibility; flood risk management; urban adaptation

\section{Introduction}

The magnitude and urgency of the need to adapt to climate change is such that combating it has been taken up as one of the sustainable development goals-Goal 13 (SDG13) by the United Nations [1]. In addition to this urgency, the uncertainties related to climate and other societal factors have to be taken into account more rigorously while planning and implementing practical water management measures [2]. The most common approach to adaptation planning is based on 'singular perspectives' such as looking at the issues from either technical, political or other perspectives, or in often separated sectors such as urban development, drainage, transport or public health [3]. There are concerns that the individual adaptation strategies arising from these differing perspectives might lead to maladaptation; i.e., increase the vulnerability of other sectors, systems or groups, or lead to inefficiencies in implementation [4]. In each case there is a need to assess the risk of maladaptation ideally from the beginning and throughout the adaptation planning process [5]. 
The outcomes of adaptation planning generally reflect the perspective (lens) through which the adaptation challenges have been analysed. This is because there are defined frameworks, i.e., the basic structures or underlying concepts, which guide response assessment in particular domains and hence the nature of the outcomes. Frameworks tend to 'narrow down' an issue using a particular perspective to structure the adaptation challenge-i.e., arranging it according to the concept, identifying patterns to account for, or sequencing accordingly-in order to get the outcome desirous by the perspective. From a social perspective for example, this involves enhancing or maintaining the liveability of part of an urban area. There are recent integrated adaptive policy planning mechanisms such as dynamic adaptive policy pathways [6] that bring flexibility into the perspective, accommodate multiple perspectives and are also geared for unexpected feedback mechanisms. However, these planning mechanisms are difficult to implement as prevailing practices are not sufficiently flexible [7]. Dupuis and Knoepfel [8] in reviewing the climate change adaptation plans and their subsequent implementation in Switzerland and India, state that, in-spite of the decision makers' desire for framing adaptation policies, they encounter difficulties in implementing adaptation practices. In The Netherlands, adaptation based on flexibility and learning_although appreciated from a planning perspective-is seen to be less credible and without clarity by the general public and many stakeholders, resulting in resistance to implementation [9]. Regardless of the adaptive capacity of the country, climate change adaptation has serious implementation issues [8,9]. Lack of managerial flexibility in implementation is also often attributed to the "command and control" nature of the policies that govern the implementation of adaptation measures [7] and can also be the result of protectionism, or failures to cooperate, between constituent parts of the same organization [10].

The objective of this paper is to present a framework for structuring the local adaptation responses using the inputs from multiple perspectives. The resulting comprehensive approach will help to better understand and bridge the gap between climate adaptation planning and adaptation implementation in an urban environment that is currently adapting to climate change, focusing on flood risks.

The approach taken in this paper is to provide a means to enhance the managerial flexibility to adapt and to reduce the risk of maladaptation, by structuring the adaptation challenges through multiple perspectives, and by looking at the link between the adaptation measures and parameters across perspectives. We understand and define parameters as external drivers such as sea level rise, rainfall acting on the system and endogenous factors such as poverty or household incomes within the system. Enhancement of managerial flexibility is achieved by implementing measures in the immediate term or longer into the future, or the implementation of other measures that can lower the risk of over or under investment. While the quantification and identification of flexibility in contributing to adapting to future events is still the subject of much ongoing research [11], the approach set out here contributes by explicitly addressing the means of identification and of increasing flexibility to respond among the various optional adaptation measures.

The paper is organised as follows: (i) an Introduction Section—this section-where the challenges faced due to current planning and implementation approaches to climate adaptation are introduced; (ii) a Background Section where the theory of single, dual and multiple perspectives are explained in addition to the implementation practices and related implementation issues; (iii) the Methodology explaining how the climate adaptation challenges from a context of flood risk management can be better analysed, together with the procedure for creating the framework; (iv) the Framework Section, where the findings from the analysis of the literature reviewed and examples are presented in the form of a framework that can be used to help structure adaptation challenges from a multiple perspective; (v) a demonstration of the framework of flood management using a case study in Can Tho and finally; (vi) Discussions and Conclusions where the findings are synthesised and considered for application in other contexts and situations. 


\section{Background}

\subsection{Contemporary Adaptation Planning Perspectives}

Climate adaptation is frequently being examined through various singular perspectives-i.e., based on domain specific points of view or a particular attitude or way of looking at something-such as societal, engineering, planning, economics or vulnerability reduction perspectives [12-16]. Such singularity of perspective may be an example of Kant's "Anschauung" [17] where the means of human acquisition or receptivity of knowledge is via what is presumed to be intuition, 'normal' thinking. However, climate change does not conform with a typical decision makers 'normal' problem, i.e., a problem that is recognised as fitting with a decision makers' usual intuitive view of the world.

Notwithstanding, there are also examples of studies taking a dual perspective such as those considering socio with other domains such as technical, economic, cultural or equityinclusiveness [16,18-20]. Eriksen, et al. [21] argue that there are multiple perspectives to climate adaptation and present the "Fifth Assessment Report of the Intergovernmental Panel on Climate Change" IPCC [22] as evidence. As illustrated in Chapters 8, 14 and 15, the report clearly recognises the need for social and political perspectives, as well as technical perspectives for effective adaptation to climate change. Such consideration of multiple perspectives requires careful attention to the: (i) progression of drivers-e.g., sea level rise, rainfall, GDP, urbanisation-that constitute the context in which adaptation happens; (ii) uncertainties attached to the projection of the drivers in the future scenarios; (iii) robustness of adaptation measures in the future across scenarios [23].

\subsection{Challenges in Structuring Adaptation Responses}

Adaptation is complicated in ways that are not easily explored in quantitative and macro-scale studies, where the complexity of adaptation is often trivialised in the pursuit of quantification [24]. The simplification of adaptation problems and responses can be attributed to: (i) the practice of analysing adaptation through singular perspectives in silos where there is a trade-off between the desire to make correct decisions and to minimize the effort [25]; (ii) Einstellung or heuristic effects-cognitive mechanisms that prevent decision makers from spending time and effort looking for alternative solutions to a problem when they believe they already have "an adequate" one based on what has "always been done". This effect inhibits even experts in expending effort in examining the crucial features of the problem even when detailed information is available [26]. Over a period of time, simplification of a type of problem in order to readily understand or grasp it, often leads to heuristic based decision-making that can embed systemic errors as well as trivialise the issues. Adaptation planning needs to be considered as a complex problem, as complexity or a wicked problem and approached using a framework such as that for a complex adaptive system [27-30]. This requires a systems approach, seeing "systems as a whole"; where problem structuring and solving requires an understanding not just of the components of the system, but also of their interrelationships and their relation to the whole (e.g., Young and Hall [31], Von Bertalanffy [32]). Approaching systems as a whole and an understanding of whole system behaviour, for example of flood risk management systems, are recognised as important steps in strategic flood risk management system understanding [33].

\subsection{Gap between Adaptation Planning and Implementation}

Climate adaptation in domains such as flood risk management is a conundrum, as: (i) the main adaptation interventions are long-lived, capital intensive and largely irreversible [34]; (ii) the decision making for adaptation is beset with uncertainties, which necessitates an approach that is flexible and in itself adaptive to the system changes and also to other changes [35]. Flexibility is seen as a desirable feature that enhances system capabilities and functionality [36] and lessens the effects of maladaptation throughout the entire life cycle [37]. In one of the largest scale attempts at flexibility in adaptation, the Delta program in The Netherlands is based on adaptive delta management. This recommends a flexible approach as a means for implementing measures in the immediate term or somewhere in the 
future-i.e., to speed up or defer implementation of adaptation measures, or implement other measures that can prevent the risk of over or under investment [38,39]. The ability to modify investment decisions is referred to as 'managerial flexibility' [40]. Incorporation of flexibility with respect to implementation of climate adaptation measures is provided in various ways: such as allowing midterm adjustments and modifications of structure [41,42]; keeping investment or implementation measures open for future adaptation $[43,44]$; postponing adaptation until the time when the cost of further delay would be more than the benefits [45].

The following barriers to flexible arrangements have been identified [7]: (i) policy makers' preference for robust arrangements; (ii) detailed contracts as modus operandi; (iii) existence of one powerful actor; (iv) divisions between policy making and policy implementation; and (v) underestimation of required implementation space. It follows from the above that interim adjustments in the implementation process may affect adaptation strategies being implemented simultaneously in other domains or spatial levels and that an ex ante analysis of the (potential) interdependencies between these strategies is not yet common [46]. The implementation issues continue to remain capricious, which requires understanding of the capabilities of actors; and the influence of factors such as a natural disaster or shift in markets on the actors involved [47]. The lack of clear roles and responsibilities for actors in an integrated flood risk management approach is also often a barrier for the implementation of flexible arrangements [33].

Hence it is clear that there is a gap between the adaptation planning and implementation of adaptation measures, which is a problem that impedes effective climate adaptation. These gaps are due to: (i) singular perspectives on adaptation [3]; (ii) a lack of flexible implementation arrangements [7]; (iii) the trivialisation of complexities [24]; and (iv) an absence of proactive analysis of implementation issues [47]. The gap between policy making and implementation as well as the underestimation of implementation space can be overcome by properly structuring the adaptation planning problem, where also the measures that are selected for implementation are understood in relation to each other and to the system as a whole. Problem framing-by conceptualising the problem based on multiple perspectives - enables better understanding of the adaptation policies, gives them meaning, renders them manageable and helps in the choice of polices that are implementable [48,49]. There are a number of adaptation problem framings such as adaptation to climate change, adaptation to climate variability and vulnerability centred adaptation [8,22]. Although there could be a common understanding at a national level about the suitability of a particular climate adaptation framing, differences frequently persist at regional and local levels among the various actors in implementing consequent adaptation policies [7-9].

\subsection{Understanding Adaptation in a Local Context}

Although adaptation is mainly driven by global, regional and federal initiatives (e.g., IPCC [22], EEA [46], Infrastructure Victoria [50]), adaptation is mainly about the quality of local knowledge, local capacity and willingness to act at household level and local government level [51]. In adapting to floods, many households resort to autonomous adaptation practices in the short term such as moving valuables to higher levels during flooding and in the longer term, in refurbishing houses and subscribing to insurance policies to minimise losses (e.g., Rozer et al. [52]). Whereas local governments along with federal agencies resort to policy driven initiatives such as emergency responses in the short term and may invest in major infrastructure such as drainage systems and sea walls for the longer term [15]. Urban planners, sociologists and economists describe cities as self-organising systems where there is an emergent bottom-up process creating distinct neighbourhoods and unplanned demographic, socio-economic and physical clustering [53]. The presence of a local adaptation capacity and its evolution may be attributed in part to this emergent nature of neighbourhoods [51]. Emergent neighbourhoods are the outcome of myriad interactions and emerge bottom-up due to the interaction of individual choices and actions of many human agents (e.g., households, business, governments) and bio-physical agents (e.g., climate, natural disturbances) [53]. Resilience to flooding is therefore recognised as an emergent property of individual, community or organisations in strategic 
flood management [33]. The individual's or household's vulnerability and capacity to adapt are influenced by social, economic, political and environmental factors. The complex relationship between these factors at a local level needs to be understood while analysing the particular situation in any urban area before taking up adaptation [54].

The type of adaptation measures selected depend upon how the adaptation problem is framed using framings such as adapting to climate change or adapting to climate variability or vulnerability centred adaptation [8]. For example, adapting to the changing climate might lead to future risk reduction measures such as an increase in dike heights [42,55], whereas, adaptation to climate variation might lead to risk recovery measures such as insurance and post disaster relief assistance [56] or a vulnerability centred adaptation might encourage enabling low income groups to cope with floods [57], (e.g., resettlement of vulnerable populations [58]). Although these measures originate from different perspectives, there is the possibility of synergies between the adaptation measures originating from the various multi-sectoral perspectives adopted in an urban environment [59]. Adaptive capacity and flexibility are likely to increase due to the synergy between the adaptation measures [60]. For example, many cities in developed countries across the globe such as Bangkok and Rotterdam are now exploring the opportunity to gradually adapt the urban fabric to flooding using on-going urban renewal activity [61]. In order to understand these synergies, the relationships between adaptation measures and drivers that act upon them have to be understood. In this, localised investments and efforts made by households and communities towards adaptation are rarely considered at a city or national level while planning for major adaptation measures [51]. There also needs to be an understanding of the interrelationships between the adaptation measures. Analysed together, the autonomous adaptation measures at household level and policy driven adaptation at city level, can reveal the (often hidden) mechanisms available for scaling up or ramping down of adaptation measures, delaying or speeding up the time of implementation of adaptation measures (i.e., flexibility). Also the consideration of the widest set of actions that reduce the probability and consequences of flooding is an important principle of strategic flood risk management [33]. This should be better explored for inherent flexibility—-to implement—in an emergent urban context through pooling and analysing the adaptation measures from various perspectives and levels.

\section{Methodology}

An analysis of the current published adaptation plans through review of the literature (e.g., $[3,12-16,37,42,57])$ provided the insights and requirements to define the individual steps in structuring an adaptation problem. Based on these findings a framework has been developed to enable the structuring of climate adaptation challenges though taking a multiple perspective. The adaptation problem structuring framework (Figure 1) is based on: (i) a systems approach - the systems approach has been partially used where the urban area is considered as a system, i.e., "system as a whole" in order to understand the interactions and relationships [31,32]; (ii) existing climate adaptation framings that look at impacts, adaptation and vulnerabilities [22,62]; (iii) contemporary approaches that are prevalent in identifying and incorporating flexibility to adapt $[37,42,43,60]$; (iv) proactive analysis of implementation issues during adaptation [47]; and (v) inclusion of local context and integration with other planning processes [33]. To demonstrate the applicability of the framework a case study has been used: Can Tho, Vietnam. The multifarious ongoing climate adaptation plans for Can Tho in Vietnam provide an example to demonstrate the applicability of the framework. It is important to note that the focus here is on the compatibilities and synergies; and, not all the aspects of the framework are illustrated in this case study, such as those dealing with maladaptation and trade-offs. 


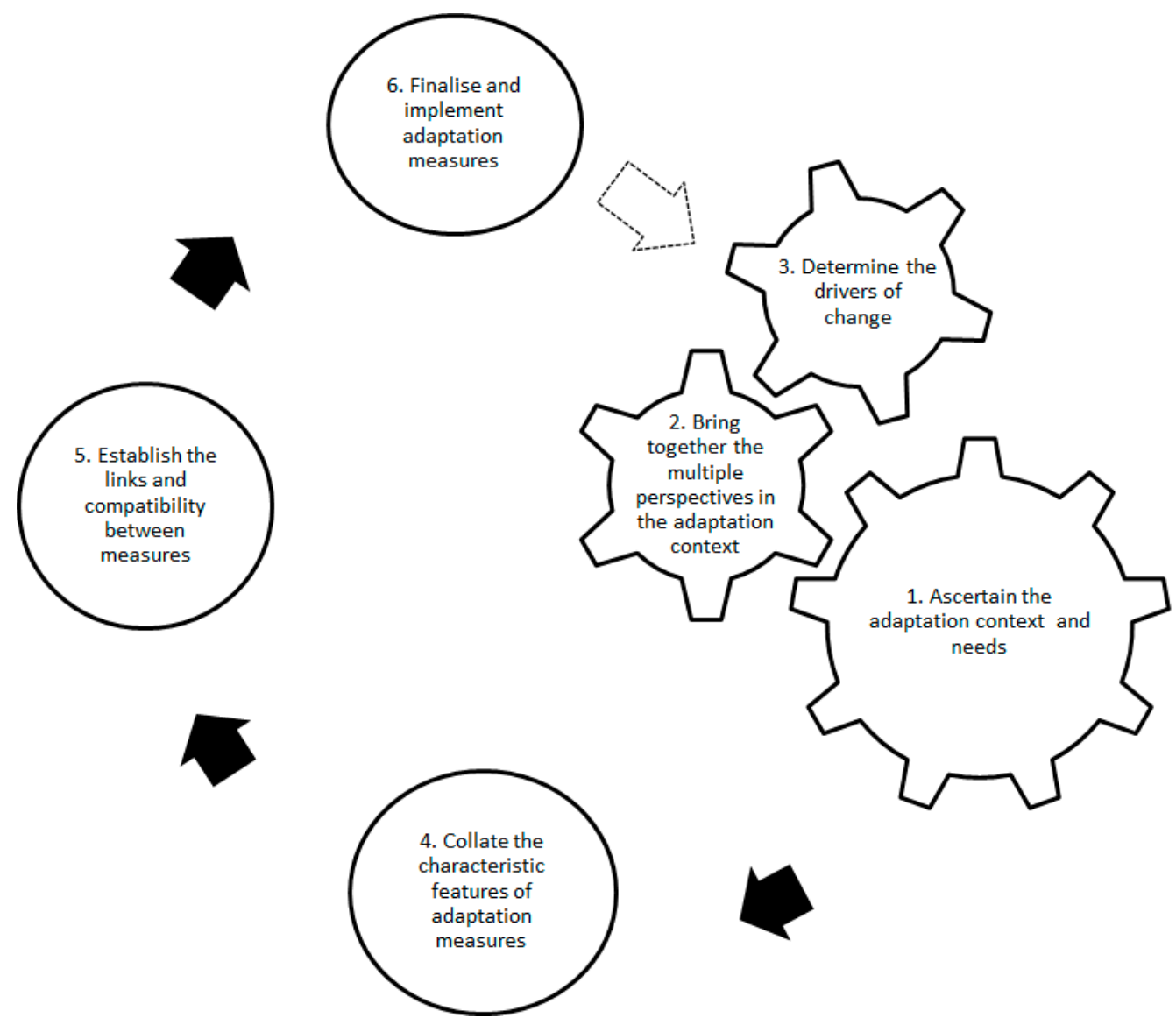

Figure 1. Framework for context specific structuring of climate adaptation responses. The illustration comprises a framework based on multiple perspectives as well singular perspectives. The individual steps (1-6) connected by the dark arrows constitute the comprehensive multiple perspective framework. The white arrow enclosed in black dotted lines represent the feedback and learning from implementation stage to the subsequent adaptation responses that would reduce the gap between planning and implementation.

\section{Framework for Structuring Climate Adaptation Responses Using Multiple Perspectives}

In order to structure the climate adaptation "responses", it is essential to understand the context in which adaptation is happening-i.e., the stressors in the context, perspectives, drivers in the context, adaptation measures in these contexts and the relationship between them. The sensitivity of the system to the stressors and the link between adaptation measures can be identified from existing literature. However, exhaustive literature may not be available in all contexts. In such instances stakeholder consultations should be conducted to determine the multiple perspectives, stressors, and sensitivity modelling could be used to give a sense of what the key drivers are in the context.

A six step generic framework has been defined for context specific structuring of a climate adaptation problem (Figure 1) using multiple perspectives. This is further explained in the following section. The framework is set out to as a representation of a strategy where adaptation context, drivers of change and multiple perspectives help in determining the features of adaptation measures and the links between them. Although the objective of solving the adaptation problem tends to shift the focus and importance to the implementation of measures, the framework emphasises the background elements that are required for successful problem solving. The three interlocked gears-"ascertain the adaptation context and needs", "bring together the multiple perspectives in the adaptation context" and "determine the drivers of change", form the core of the framework; which then guides the decision maker to "collate the characteristic features of adaptation measures", and "establish the links and compatibility 
between the adaptation measures across perspectives"; and finally culminates to "finalise and implement adaptation measures". The steps are numbered for sake of understanding and do not necessarily indicate the sequence. The framework can begin with step 1 and end in step 6 but alternative entry points can be selected (general flow direction is indicated by dark arrows). The framework also comprise a feedback or learning process (indicated by the white dashed arrow) from the implementation stage to the subsequent adaptation responses that could helping in reducing the gap between planning and implementation of adaptation measures.

\subsection{Ascertain the Adaptation Context and Needs (Step 1)}

What is the context in which adaptation is taking place? Adaptation towards a single predominant stressor? Or adaptation for multiple stressors? Stressors are the set of drivers that expose the vulnerability of a community [63]. Some of the stressors leading to adaptation are climate change, climate variability, land-use change, degradation of ecosystems, poverty and inequality [64]. As adaptation is context specific it is pertinent to find out the changes to which adaptation occurs, i.e., if the adaptation is to cope with climate change or is there adaptation to cope with other aspects as well, such as adapting to socio-economic changes and adaptation to political changes? For example, it is common to see adaptation in countries such as the UK and Netherlands to single stressors such as climate change, due to drivers such as sea level rise and rainfall increases [37,42]. Although definitive evidence is lacking and it is not possible to generalise too much, it may be that in typical developed countries, the socio-economic regimes are more well-developed and stable than for many developing countries. However, the relative stationarity of socio-economic stressors or the magnitude of impact from these stressors is likely to be less than that of stressors like climate change which is all pervasive. This may explain why there is a narrower focus on a single stressor, like climate change in many developed countries. In contrast, in developing countries, they are trying to cope not just with climate change but with all other aspects of a growing economy, which implicitly requires a more multi-perspective approach $[62,65]$.

\subsection{Bring Together the Multiple Perspectives in the Adaptation Context (Step 2)}

There may be a requirement to address multiple perspectives for adaptation even due to a single stressor. Climate risks, impacts and adaptation are location and context specific $[62,66]$ and all of the prevailing perspectives on adaptation available in the set context-single and multiple - should be ascertained. For example if the adaptation need is driven by climate change there could be an infrastructure oriented perspective, planning perspective, socio-economic perspective, ecological perspective, political perspective, etc. Each and all of these perspectives have to be considered. The review of publications, including adaptation plans and literature would be sufficient to ascertain what the multiple perspectives were. However, this may not be adequate for all cities, especially where there may not be existing plans. For these, the identification of single and multiple perspectives could be undertaken through an exhaustive stakeholder consultation to identify as many perspectives as possible.

\subsection{Determine the Drivers of Change (Step 3)}

There could be a single driver (such as rainfall increase) driving adaptation or multiple drivers (such as rainfall, sea level rise, increase in population) driving the need to adapt. It is necessary to determine all the drivers that drive the change in the set context and check if the drivers are independent of each other or linked. How are these drivers affecting the urban area? How are these drivers changing over time? Is there a certainty or uncertainty about the progression of drivers over time? For example, if the adaptation in a city is towards coping with climate change impacts, the perspective could be driven by drivers such as rainfall and sea level rise that may determine the magnitude of flood depth. The same city could also adapt in parallel to economic change due to a driver such as GDP growth. The change in GDP might affect the income levels, which in turn 
might have a bearing on vulnerability to floods. Hence the convergence of rainfall, sea level rise and GDP growth as driver-climate and socio-economic change-need to be considered in terms of the effect on vulnerability to flooding. The effect of drivers such as river water level and urbanisation on vulnerability of households to flooding could be seen during the analysis of adaptation in Ho Chi Minh City, Vietnam [67]. Similarly in developing countries where there is urban upgrading or socio-economic progress, there is typically a gradual improvement in housing conditions and access to social services such as healthcare or education [68] and the effect of this on vulnerability to flooding should be taken into account by considering the consequent reduction in vulnerability. The unaccounted for vulnerability reduction or enhancement can be attributed to the silo or compartmentalised thinking arising out of single perspectives. This is also true for other institutions or departments even in the same organisation, such as roads vs. drainage; sanitary vs. storm water; ecology vs. infrastructure, etc. For example in the UK, early improvements, such as the Clean Air Acts in the 1950-1960s controlled the worst of the air pollution arising from industrial emissions-known as 'smog', whereas the less obvious but as potentially damaging to residents health that has grown in impact since then, is pollution from vehicle emissions that has not been tackled [69] as a result of silo thinking.

\subsection{Collate the Characteristic Features of Adaptation Measures (Step 4)}

It is necessary to collate each of the adaptation measures recommended or implemented from all of the various perspectives. Determine the characteristic features of adaptation measures such as: (i) nature of measure-hazard reduction or vulnerability reduction; (ii) explicit external factors that trigger or determine the implementation and magnitude of measures; (iii) level at which a measure is being applied such as city level, neighbourhood level or property level; (iv) emergent or autonomous measures, that are not planned and supported by city or government agencies but are bottom up responses that emerge from a local adaptation context. For example the dikes built to prevent the flooding of urban areas typically fall under the category of being a hazard reduction measure (one funders' responsibility). This is also a measure which is planned at a city scale and is directly influenced by the external drivers such as rainfall and sea level rise. Examples of autonomous measures emerging from a local context are temporary flood barriers around properties, elevation of floor levels of buildings in response to flooding. The conducive or constraining environment for emergence or autonomous measures depends upon the prevailing building, planning and land use regulations. At the least there are issues with the autonomy of the population and the regulatory system with regard to emergence or autonomous measures in developing countries. In developed countries this autonomy is severely constrained. For example, in Brisbane prior to the 2011 floods, a resident who was an engineer with a PhD wished to raise the level of her traditional 'Queenslander' property. She raised it the maximum allowed by the City ordinances, although she wanted to raise it further. She was flooded in 2011. After the event the City changed the ordinance to allow higher floor levels, but she had already invested heavily and could not afford to raise the property any higher [70].

\subsection{Establish the Links and Compatibility between the Adaptation Measures across Perspectives (Step 5)}

Measures for risk reduction and adaptation require consideration of the dynamics of vulnerability, exposure and their linkages with socio-economic processes [62]. Upon identifying the nature of each measure, the linkages between the adaptation measures across perspectives should be established in line with system approaches, such as Von Bertalanffy [32], which recommends ascertaining the nature of the links between the various components of the systems and to the system as a whole. These linkages would also help in establishing or re-establishing the functionality of a measure through a combined perspective. Also, upon determining the nature of the measure it is possible to establish if the adaptation measure is being driven by a single driver or if there are additional or secondary drivers that might have a strong or weak influence over the measure. For example as discussed in Step 3 above, the economic driver such as an increase in GDP might lead to urban upgrading and poverty reduction, which in turn can result in the autonomous reduction of vulnerability. Further, 
green urban drainage infrastructure measures comprising rainwater tanks, green roofs, rain gardens, wetlands-known as Low Impact Development systems (LID), Water Sensitive Urban Design (WSUD), Sustainable Drainage Systems (SuDS) and Best Management Practices (BMPs) [71]—are increasingly gaining acceptance across multiple perspectives such as engineering, liveability, sustainability and resilience [72] and could be expected to be utilised as responses that provide multiple types of outcome and are at the same time flexible.

Compatibility between adaptation measures: Does the synergy due to combinations of measures facilitate the achievement of the adaptation objective in an effective or efficient manner? Does the combination of adaptation measures hinder achievement of the adaptation objective? The various adaptation measures collated across perspectives may be compatible. For example, from an analysis of the adaptation measures in some of the Deltas around the world (e.g., Ganges, Mekong, Chao Phraya, Rhine, Mississippi) at city and household scales $[60,61,73]$ it may be concluded that: (i) the estimated functional life span of the city scale flood protection measures could be enhanced by including the coping measures that are practiced at the household level; (ii) consideration of coping capacities could be more effective in planning adaptive flood prevention measures such as spatial planning, where more extensive inundation could be accommodated in certain parts of the city.

\subsection{Finalise and Implement Adaptation Measures (Step 6)}

When it comes to successful adaptation planning, structuring the adaptation problem is only a part of the goal. In order to have an effective outcome the measures identified have to be sequenced and evaluated in a way that is easily understood by decision makers. Adaptation pathways and Real-in options are some of the methods that allow for flexible implementation of adaptation measures in urban flood risk management as uncertainties are revealed over time [37,42]. Adaptation pathways may be generated using a precedence-based data specification template-description of measures and their relations in a logical and compact manner. Evaluation framework such as XLRM [74] provides scope for ascertaining the performance of adaptation measures or adaptation pathways over a combination of drivers. Selection of an adaptation pathway for implementation from among these pathways can then be made using set thresholds or Net present value or likelihood of occurrence among all plausible scenarios. The following section provides a demonstration of application of the framework.

\section{Analysing Climate Adaptation Planning and Implementation in an Urban Context: Can Tho, Vietnam}

Can Tho is one of the fastest growing cities in the Vietnamese Mekong Delta [55]. Can Tho is located on the banks of the Bassac river (Figure 2) and the average elevation of the city is $1.5 \mathrm{~m}$ above mean sea level [55]. There are various singular and dual perspectives being taken and a broad body of research and other literature on climate adaptation for Can Tho. Also, there is unanimous agreement among the various studies (e.g., Mekong Delta plan [75], World Bank flood resilience report [55], Pathirana et al. [65]) that there is an adaptation gap in Can Tho in responding to climate change, as the city is located in the Mekong Delta, which is especially vulnerable to climate change [76]. One of the prime reasons for choosing Can Tho as the example presented here is the authors' direct experience of various issues in Can Tho such as urban flooding, drinking water supply improvements, water quality impacts and climatology issues and the formulation of the potential responses to address these. In the example, for clarity the adaptation responses considered are restricted to two groups only: the traditional institutionally led large-scale inundation risk reduction measures; and the local, typically bottom-up and emergent responses of local dwellers, raising the floor levels in their properties. These are examples of a singular 'protect' perspective and a local 'social' perspective respectively. The example demonstrates how, by taking a dual perspective from the outset and integrating both of these singular perspectives, considerably greater benefits can be obtained. 


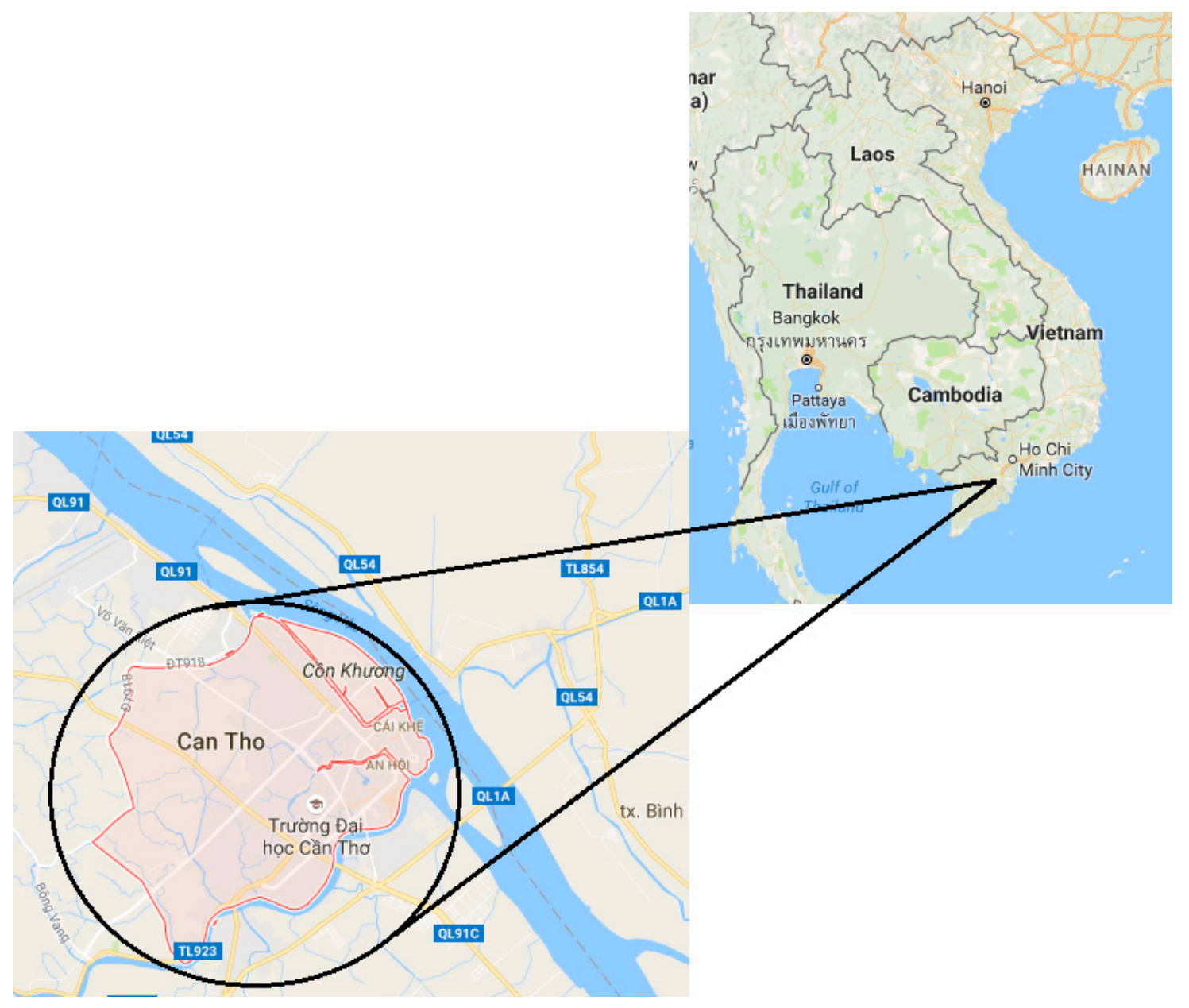

Figure 2. Map showing location of Can Tho (Source: Google Maps Website, https://goo.gl/maps/ 6D73uLoJYj82).

\subsection{Ascertain the Adaptation Context and Needs (Step 1)}

Can Tho is being threatened by the consequences of climate change, as for example, a $1 \mathrm{~m}$ rise in sea level rise would expose about $50 \%$ of the entire delta area to floods [75]. The city is also likely to be affected by an increase in river water levels due to sea level rise; an increase in river discharge due to increase in rainfall, deforestation and river training works upstream; and an increase in urban runoff due to rainfall and increased imperviousness [77-80]. The rapid urban development in Can Tho has led to unplanned growth, increase in real estate prices, widespread water pollution and flooding issues and prevailing social disparities in terms of availability of housing stocks and access to services among the residents [81]. Can Tho is adapting to climate change as well as socio-economic change and to a certain extent is still adapting to the political changes after the Indo-China war $[65,81,82]$. Hence there are multiple stressors and multiple adaptation contexts in Can Tho to changing climate, urbanisation and economic situation. In countries such as Vietnam, adaptation can be seen as being driven by multiple stressors such as climate change, land use change and poverty [83], as is evident from the analysis of the urban adaptation that is currently underway in Can Tho.

\subsection{Bring Together the Multiple Perspectives in the Adaptation Context (Step 2)}

There has been considerable climate related research for Can Tho, but there is a significant gap between knowledge and practice [84]. Considerable research has also been conducted in the City that considers multiple perspectives-vulnerability reduction, institutional, planning, 
water quality, infrastructure improvements-concerning climate change and adaptation at multiple levels $[19,55,58,77,81,85-88]$. The traditional engineering perspective is reflected in the recent flood risk management plans that are being prepared and considered for implementation, where the emphasis is more on avoiding floods by means of: (i) dike rings; (ii) improvements to drainage systems; (iii) and increasing the freeboard of flood defence systems, roads and houses by $50 \mathrm{~cm}[55,85,89]$.

In contrast with the traditional engineering perspective, the social and socio-economic aspects of flood risk management in Can Tho illustrate the experiences of living with water by the residents: tolerance to flooding; coping measures being taken at household level; direct and indirect damage to households. These are all the factors that trigger the households to implement household measures [55,81,83,87,90,91]. In spite of having a high level of preparedness: (i) the damages due to flooding in households is high in Can Tho, sometimes becoming intolerable by exceeding several months of income; and (ii) the losses due to disruption of business are higher than the loss due to the physical damage in small business establishments [91]. This is a critical finding, as the people who are vulnerable to flooding are in the lowest income groups who cannot afford adaptation measures themselves. In this case income levels have a direct correlation with the implementation of household adaptation measures, such as elevating property floor levels [81]. Here we focus on the singular perspectives above, the 'traditional engineering' and the household coping measures to illustrate the need to take a multi-disciplinary perspective.

The Mekong Delta plan (MDP) [75] looks at the climate adaptation from a Delta and regional perspectives. MDP [75] looks at adaptation as a strategic issue where there is an interplay between climate change related water management and economic development. The plan advocates the traditional system for the delta of living with the floods that is based on controlled flooding, which is best suited for rural areas [73]. The socio-economic aspect is not very well reflected in the adaptation measures, where the measures are mostly infrastructure and spatial planning oriented and less on the vulnerability reduction aspects.

Thus it is apparent that there are multiple adaptation perspectives-such as engineering, socio-economic, regional perspectives-in Can Tho and therefore there is the possibility to exploit the synergies between these various individual perspectives.

\subsection{Determine the Drivers of Change (Step 3)}

A number of external factors contribute to the flooding and hence the flood risk management of Can Tho. External factors such as sea level rise and rainfall increases lead to increases in flood depth and frequency $[77,78,80]$. Externalities such as economic growth rates influence: (i) urbanisation which in turn has a direct bearing on increasing imperviousness and enhanced runoff in Can Tho [77]; (ii) economic status such as household income and number of poorer households [92,93]. The repercussions of macro-economic growth in Can Tho may be observed in the recent trends in the population increasing due to migration, urbanisation, social disparity in terms of income and real estate prices [81]. Instruments, including developmental plans at a regional level, city level and community level influence the micro and macro urban attributes such as rate of urbanisation, liveability, aspirations of the people, poverty levels and capacity to adapt at multiple levels $[47,75,82,94]$. Also the aforementioned external factors are beset with uncertainty, which complicates how best to plan for overall adaptation [63,95]. The list of drivers in Can Tho includes sea level rise, rainfall increase, urbanisation, household income, social disparity and developmental plans.

\subsection{Collate the Characteristic Features of Adaptation Measures (Step 4)}

A set of adaptation measures being planned and implemented in Can Tho at various levels can be elicited from the existing adaptation plans. Measures are at a city level and implemented by the State or central agencies under the umbrella of flood protection, such as increasing dike heights, improvements to drainage systems and increasing the freeboard of roads and important buildings $[55,75,85,89]$. These measures are based on a predetermined maximum river water level in 
Can Tho (design value) which is based on the observed water level in the River Hau. The adaptation tipping point-i.e., the time in the future at or after which; or the value of driver at which or above, where the adaptation measures are no longer effective [43] — for these measures occur once the water level reaches the design value. A return frequency ( 1 in 100 Years) is built into this design value. Measures such as spatial planning and urban waterscapes are also proposed [75]. Urban development plans such as beautification of canals and lakes, resettlement of people from vulnerable areas, have been implemented in Can Tho [58,81]. Furthermore, a set of household adaptation measures such as elevating the floor levels, street level measures such as construction of temporary dikes during the flooding season have also been implemented [19]. An increase in the number of households adapting to floods since 1960 has been apparent [19], establishing that there has been emergent behaviour resulting in autonomous household level adaptation-influenced by flood depth, income level and property ownership.

\subsection{Establish the Links and Compatibility between the Adaptation Measures across Perspectives (Step 5)}

Consideration of autonomous adaptation in households of Can Tho at the planning perspective may presume this to be entirely emergent and driven by a mix of exogenous and endogenous factors. However, there are nuances in increasing the floor level of houses that are linked to physical and economic constraints. The physical constraint is the major structural modifications to doors, windows and roofs if the floors are to be raised above $50 \mathrm{~cm}$, whereas the economic constraint occurs in the form of a rapid increase in costs-almost five times-between elevating up to $50 \mathrm{~cm}$ and above $50 \mathrm{~cm}$ [83]. There are a number of households where it is deemed essential to elevate the floor levels but they cannot do so due to their low income levels [91]. The failure of decision makers and key agencies to understand these intricacies of physical and economic limits on adapting can lead to tensions while implementing these measures or lead to the failure to attain flood risk management objectives. Further, positive correlations have been established between the household income and elevation of floor levels of households, i.e., high income households have higher floor levels [81]. This insight helps in linking the socio-economic development plans such as poverty reduction [94], which aims at increasing household incomes, and this in turn could help to trigger household adaptation measures, which is a positive feedback. It is possible therefore to be more effective to directly fund poverty reduction rather than invest in major flood management infrastructure. This could be interpreted as increasing flexibility; as the decision makers have more subsequent choice by doing this to achieve the desired objectives in managing urban flooding and the measures are more widely dispersed in a number of small, local adaptations, rather than in large, irreversible and locked-in to use dikes. This dual perspective analysis reveals the inherent flexibilities that can be more effectively utilized.

This is an example of how some of the adaptation measures understood by taking a multiple adaptation perspective in Can Tho can be better linked, and thus should not be considered in isolation.

In order to exploit the synergies between the adaptation measures across the perspectives, it is vital to identify the links between these measures and the external factors that act upon the links, i.e., the factors that enable, strengthen, weaken or hinder such links. The effect of an external factor such as from sea level rise on river water levels and hence the flood levels that necessitate heightening of dikes is direct, as is the effect of poverty reduction measures that reduce the vulnerability of poorer households to flooding. Based on a traditional engineering perspective, the usefulness of a dike in Can Tho ceases when the water overtops the dike; whereas the societies' perception of flooding reveals that dwellers tolerate and cope with flood waters up to $20 \mathrm{~cm}$ in depth within their houses [87]. This tolerance may be used to extend the usefulness of the traditional engineering measures. By for example, designing dikes to be structurally safe during overtopping. These perspectives—engineering and social—put together, can therefore increase the range of drivers against which the acceptable performance is provided. The functional life span of the dikes can be increased as the concept of 'living with water' is embedded into the setting of performance thresholds for the larger scale infrastructure measures [60]. This, when considered together with the recorded household floor 
elevation measures [19], postpones the tipping point of dike elevation measures [60]. The city level dike heightening measures and the household level measures are compatible and complementary.

\subsection{Finalise and Implement Adaptation Measures (Step 6)}

The various adaptation measures proposed for Can Tho could be considered together and assessed using adaptation pathway approaches [43]. Model driven pathway approaches (e.g., Haasnoot et al. [96], Kwakkel et al. [97]) use physically based models such as hydraulic models and scenario generation techniques to find out the most promising pathways in terms of performance robustness towards multiple objectives. Selection of an adaptation pathway for implementation from among these pathways can be made based on: (i) set thresholds such as estimated annual damages (e.g., CRIDA [98]); (ii) the net present value of pathways (e.g., Gersonius et al. [37]) or benefit cost analysis (e.g., Aerts et al. [99]); (iii) likelihood of occurrence among all plausible scenarios (e.g., Buurman \& Babovic [100]); (iv) assessing all the aforementioned 'objectives' using multi-objective evolutionary algorithms which could avoid the narrowing down to a pathway based on aggregated objectives (e.g., Kasprzyk et al. [101]). Hence it is theoretically possible to identify an adaptation pathway that results in lower estimated annual damages and has the highest net present value for the combination of drivers that are most likely to reoccur at low intervals. This step has not been fully evaluated in this paper and thus should be considered as a recommendation, which has to be further tried and tested in future work.

The specific learning or findings in Can Tho thorough the application of the framework in the adaptation context of Can Tho is summarised in Table 1.

Table 1. Multiple (dual) perspective adaptation problem structuring in Can Tho.

\begin{tabular}{|c|c|}
\hline Problem Structuring Framework & Structuring Adaptation Problem in Can Tho \\
\hline Ascertain the adaptation context and needs & $\begin{array}{ll}- & \text { Adapting to climate change } \\
\text { - } & \text { Adapting to urbanisation } \\
\text { - } & \text { Adapting to economic change }\end{array}$ \\
\hline $\begin{array}{c}\text { Bring together the multiple perspectives in the } \\
\text { adaptation context }\end{array}$ & $\begin{array}{ll}\text { - } & \text { Engineering perspectives for flood prevention } \\
\text { - } & \text { Social perspectives such as living with water } \\
\text { Overall delta management perspectives such as Mekong } \\
\text { Delta Plan }\end{array}$ \\
\hline Determine the drivers of change & $\begin{array}{l}\text { - } \quad \text { Climate drivers-rainfall increase, sea level rise } \\
\text { - } \quad \text { Urbanisation—change in housing conditions } \\
\text { - } \quad \text { Economic change-household levels, income disparities }\end{array}$ \\
\hline $\begin{array}{l}\text { Collate the characteristic features of } \\
\text { adaptation measures }\end{array}$ & $\begin{array}{l}\text { - } \begin{array}{l}\text { Protection against floods-dike elevation and } \\
\text { drainage improvements }\end{array} \\
\text { Reducing vulnerability-resettlement of vulnerable } \\
\text { population in higher areas } \\
\text { - } \quad \begin{array}{l}\text { Coping with floods-elevating floor levels at households } \\
\text { (autonomous and emergent) }\end{array}\end{array}$ \\
\hline $\begin{array}{l}\text { Establish the links and compatibility between } \\
\text { the adaptation measures across perspectives }\end{array}$ & $\begin{array}{l}\text { Household coping capacities enhance the tipping point } \\
\text { of flood protection measures } \\
\text { - Household autonomous measures are driven by flood } \\
\text { levels and income levels }\end{array}$ \\
\hline Finalise and implement adaptation measures & $\begin{array}{l}\text { - Adaptation pathways approach to identify problems } \\
\text { based on single or multiple objectives }\end{array}$ \\
\hline
\end{tabular}

\section{Discussion}

In Can Tho, the so-far taken technical and socio-economic perspectives that are relevant to adaptation planning and problem analysis have not automatically led to multiple perspective problem structuring or identification. In response to this, the framework developed here has 
guided the structuring of climate adaptation problems using multiple perspectives. The multiple problem structuring framework has elucidated clear steps with which the inferences or findings from multiple perspectives could be assembled to understand the relationship between various drivers and adaptation measures. The adaptation capacities of households in Can Tho towards coping with floods would have gone unnoticed if the adaptation planning were to be done from the predominant infrastructure oriented perspective. Consideration of coping household adaptation measures from a social perspective, when combined with an engineering perspective such as heightening the dikes is likely to increase the functional life span of these. The coping capacities of households depend on their income levels and therefore cannot be presumed; however, this does give a choice to decision makers in Can Tho to invest in flood proofing of houses through subsidies or to elevate the dikes (see Section 5.5).

In Can Tho adaptation is complicated when explored at a household scale due to the interplay of a number of drivers. The assumed adaptation capacities and vulnerabilities are ultimately different in ways that are not explored in many quantitative and macro-scale studies [24]. It is possible that a problem structured with many perspectives would be challenging in application when using calculation-intensive methodologies like real in options [102] without major simplifications. In-spite of the increase in complexity, consideration of multiple-perspectives for adaptation is worthwhile as it contributes to clarity of understanding of the adaptation opportunities as well as acknowledging the many and various feedbacks in the system.

The consideration of multiple perspectives can have the further benefit of revealing the 'loss of flexibility' due to negative feedbacks. Changes in socio-economic status might lead to a change in values which could affect the individual and social perception of risk, resilience and adaptive capacity [103]. There are indications in Can Tho that the aspirations of people might become higher- "We want to become like Rotterdam" - and tolerance to floods in the future might reduce [81]. Mapping this to the appropriate socio-economic scenarios may show that as people become more affluent, their willingness to live with water in the streets may reduce [65]. Considering this will help prevent assumptions that reliance on household level adaptation will be valid under all future scenarios. Also, this understanding will help understand any risks of maladaptation, which are less apparent when seen from singular perspectives.

The case study shows that structuring climate adaptation through multiple perspectives is possible. This frame work would be used at policy level, i.e., there is a likelihood of using the framework at a national or regional level, which considers the local adaptation context such as autonomous adaptation or emergence happening at a city or household level. However, the biggest challenge lies in operationalising the framework. The usage of the framework is likely to be effective in a common stakeholder consultation forum. When adaptation planning is driven by a planning agency or any other stakeholder who has one predominant perspective or a dominant authority there are chances for biased decisions. In such circumstances there is the possibility of normative thinking, i.e., Kant's "Anschauung" [17] or heuristic effects i.e., Einstellung [26] that would hamper the implementation of the multiple perspective framework. This is most likely in countries such as Vietnam, where the cultural practices often hinder the effective dialogue between the stakeholders belonging to various hierarchies [104]. This necessitates a different form of stakeholder engagement rather than a round table format, which is prevalent in western countries. Applying the framework either top-down or bottom - up might be a challenge for taking a multiple perspective approach. Although the application of the framework is very much context specific, simultaneous application of the framework at all levels could yield better results. Inspiration for operationalising the framework could be obtained from continuous stakeholder engagement processes such as learning and action alliances (LAA) [105].

The problem structuring framework has been developed based on insights from the dual perspective analysis of adaptation in a flood risk management system and considering socio economic development and urban development as externalities. However, there are adaptation measures from 
other domains such as drought management and public health risk management which comprise climate adaptation that have not been considered. These domains would come under the ambit of the framework, provided the system boundary had been extended to cover the entire urban functions in the climate adaptation domain. Such an analysis would be expected to have revealed further potential adaptation measures, inter-relationships between measures, emergent behaviours and inherent flexibilities.

\section{Conclusions}

This paper focussed on developing and demonstrating a framework for structuring the local adaptation responses using the inputs from multiple perspectives in an urban environment that is currently adapting to climate change. A framework has been created to enhance the understanding of any local adaptation context by structuring the adaptation problem through multiple perspectives. The framework differs from the normal portfolio of measures or portfolio of approaches (e.g., UK foresight [106]) as it aims to establish the relationships between the measures across the various perspectives within the given adaptation context. The pooling together of adaptation measures derived from multiple perspectives can lead to increased flexibility by way of having a greater number of adaptation measures and increased pathways to consider. However, merely adding more adaptation measures may not automatically translate into enhanced flexibility. Enhanced flexibility is considered by means of: (i) identifying the link between adaptation measures; (ii) ascertaining the compatibility of the measures with one another; and (iii) then creating a knowledge base comprising all plausible sequences and time epochs at which the measure could be deployed based upon the unfolding of external factors. The multiple perspective adaptation problem framework can also be used to assess the risk of maladaptation and trade-offs, which is the scope for future research. The results from the case study show that multiple perspective framing of adaptation responses enhance the understanding of various aspects of adaptation measures, thereby leading to flexible implementation practices.

Acknowledgments: This research was supported by two projects (1) Cooperative Research Centre for Water Sensitive Cities (CRC), an initiative of the Australian government. (2) PRoACC (Post-doctoral Programme on Climate Change Adaptation in the Mekong River Basin) programme by The Netherlands Ministry of Development Cooperation (DGIS) through the UNESCO-IHE Partnership Research Fund.

Author Contributions: Mohanasundar Radhakrishnan wrote the paper. Mohanasundar Radhakrishnan and Assela Pathirana conceived the ideas Richard Ashely and Chris Zevenbergen contributed towards the refinement of the ideas and in structuring and finalising contents of the paper.

Conflicts of Interest: The authors declare no conflict of interest.

\section{References}

1. United Nations. Transforming Our World: The 2030 Agenda for Sustainable Development; United Nations: New York, NY, USA, 2015.

2. Street, R.B.; Nilsson, C. Introduction to the use of uncertainties to inform adaptation decisions. In Adapting to an Uncertain Climate: Lessons From Practice; Lourenço, T.C., Rovisco, A., Groot, A., Füssel, C.N., van Bree, L., Street, R.B., Eds.; Springer: Berlin/Heidelberg, Germany, 2014; pp. 1-16.

3. Vink, M.; Boezeman, D.; Dewulf, A.; Termeer, C. Action research in governance landscapes. In Action Research for Climate Change Adaptation: Developing and Applying Knowledge for Governance; Routledge: Abingdon-on-Thames, UK, 2014; p. 35.

4. Barnett, J.; O'Neill, S. Maladaptation. Glob. Environ. Chang. 2010, 20, 211-213. [CrossRef]

5. Magnan, A.K.; Schipper, E.L.F.; Burkett, M.; Bharwani, S.; Burton, I.; Eriksen, S.; Gemenne, F.; Schaar, J.; Ziervogel, G. Addressing the risk of maladaptation to climate change. Wiley Interdiscip. Rev. Clim. Chang. 2016, 7, 646-665. [CrossRef]

6. Haasnoot, M.; Kwakkel, J.H.; Walker, W.E.; ter Maat, J. Dynamic adaptive policy pathways: A method for crafting robust decisions for a deeply uncertain world. Glob. Environ. Chang. 2013, 23, 485-498. [CrossRef] 
7. Ellen, G.J.; van Leeuwen, C.; Kuindersma, W.; Breman, B.; van Lamoen, F. Adaptive governance in practice. In Action Research for Climate Change Adaptation: Developing and Applying Knowledge for Governance; Routledge: Abingdon-on-Thames, UK, 2014; p. 112.

8. Dupuis, J.; Knoepfel, P. The Adaptation Policy Paradox: The Implementation Deficit of Policies Framed as Climate Change Adaptation. Ecol. Soc. 2013, 18, 31. [CrossRef]

9. Buuren, A.; Driessen, P.; Teisman, G.; Rijswick, M. Toward legitimate governance strategies for climate adaptation in The Netherlands: Combining insights from a legal, planning, and network perspective. Reg. Environ. Chang. 2013, 14, 1021-1033. [CrossRef]

10. Cettner, A.; Ashley, R.; Hedström, A.; Viklander, M. Sustainable development and urban stormwater practice. Urban Water J. 2014, 11, 185-197. [CrossRef]

11. Maurer, M. Full Costs, (Dis-)economies of Scale and the Price of Uncertainty; IWA Publishing: London, UK, 2013.

12. Klijn, F.; Kreibich, H.; de Moel, H.; Penning-Rowsell, E. Adaptive flood risk management planning based on a comprehensive flood risk conceptualisation. Mitig. Adapt. Strateg. Glob. Chang. 2015, 20, 845-864. [CrossRef]

13. Kind, J.M. Economically efficient flood protection standards for The Netherlands. J. Flood Risk Manag. 2014, 7, 103-117. [CrossRef]

14. Bowen, A.; Cochrane, S.; Fankhauser, S. Climate change, adaptation and economic growth. Clim. Chang. 2012, 113, 95-106. [CrossRef]

15. Stern, N. The Economics of Climate Change: The Stern Review; Cambridge University Press: Cambridge, UK, 2007.

16. Kreibich, H.; Bubeck, P.; Van Vliet, M.; De Moel, H. A review of damage-reducing measures to manage fluvial flood risks in a changing climate. Mitig. Adapt. Strateg. Glob. Chang. 2015, 20, 967-989. [CrossRef]

17. Carus, P. What Does Anschauung Mean? Monist 1892, 2, 527-532. [CrossRef]

18. Newman, R.; Ashley, R.; Molyneux-Hodgson, S.; Cashman, A. Managing water as a socio-technical system: The shift from 'experts' to 'alliances'. Proc. ICE-Eng. Sustain. 2011, 164, 95-102. [CrossRef]

19. Birkmann, J.; Garschagen, M.; Van Tuan, V.; Binh, N. Vulnerability, coping and adaptation to water related hazards in the Vietnamese Mekong Delta. In The Mekong Delta System; Renaud, F.G., Kuenzer, C., Eds.; Springer: Berlin/Heidelberg, Germany, 2012; pp. 245-289.

20. Van der Brugge, R.; Roosjen, R. An institutional and socio-cultural perspective on the adaptation pathways approach. J. Water Clim. Chang. 2015, 6, 743-758.

21. Eriksen, S.H.; Nightingale, A.J.; Eakin, H. Reframing adaptation: The political nature of climate change adaptation. Glob. Environ. Chang. 2015, 35, 523-533. [CrossRef]

22. Intergovernmental Panel on Climate Change. Summary for policymakers. In Climate Change 2014: Impacts, Adaptation, and Vulnerability. Part A: Global and Sectoral Aspects. Contribution of Working Group II to the Fifth Assessment Report of the Intergovernmental Panel on Climate Change; Field, C.B., Barros, V.R., Dokken, D.J., Mach, K.J., Mastrandrea, M.D., Bilir, T.E., Chatterjee, M., Ebi, K.L., Estrada, Y.O., Genova, R.C., et al., Eds.; Cambridge University Press: Cambridge, UK; New York, NY, USA, 2014; pp. 1-32.

23. Maier, H.R.; Guillaume, J.H.A.; van Delden, H.; Riddell, G.A.; Haasnoot, M.; Kwakkel, J.H. An uncertain future, deep uncertainty, scenarios, robustness and adaptation: How do they fit together? Environ. Model. Softw. 2016, 81, 154-164. [CrossRef]

24. Toole, S.; Klocker, N.; Head, L. Re-thinking climate change adaptation and capacities at the household scale. Clim. Chang. 2015, 135, 203-209. [CrossRef]

25. Jonas, E.; Traut-Mattausch, E.; Frey, D.; Greenberg, J. The path or the goal? Decision vs. information focus in biased information seeking after preliminary decisions. J. Exp. Soc. Psychol. 2008, 44, 1180-1186.

26. Bilalić, M.; McLeod, P.; Gobet, F. Why good thoughts block better ones: The mechanism of the pernicious Einstellung (set) effect. Cognition 2008, 108, 652-661. [CrossRef] [PubMed]

27. Geldof, G.D. Adaptive water management: Integrated water management on the edge of chaos. Water Sci. Technol. 1995, 32, 7-13. [CrossRef]

28. Holland, H.J. Complex adaptive systems. Daedalus 1992, 121, 17-30.

29. Dewulf, A. Contrasting frames in policy debates on climate change adaptation. Wiley Interdiscip. Rev. Clim. Chang. 2013, 4, 321-330. [CrossRef]

30. Dunn, G.; Brown, R.; Bos, J.J.; Bakker, K. Standing on the shoulders of the gaints: Understanding changes in urban water practices through the lens of complexity sciences. Urban Water J. 2016. [CrossRef] 
31. Young, K.; Hall, J.W. Introducing system interdependency into infrastructure appraisal: From projects to portfolios to pathways. Infrastruct. Complex. 2015, 2, 2. [CrossRef]

32. Von Bertalanffy, L. The history and status of general systems theory. Acad. Manag. J. 1972, 15, 407-426. [CrossRef]

33. Sayers, P.; Galloway, G.; Penning-Rowsell, E.; Yuanyuan, L.; Fuxin, S.; Yiwei, C.; Kang, W.; Le Quesne, T.; Wang, L.; Guan, Y. Strategic flood management: Ten 'golden rules' to guide a sound approach. Int. J. River Basin Manag. 2015, 13, 137-151. [CrossRef]

34. Gersonius, B.; Morselt, T.; van Nieuwenhuijzen, L.; Ashley, R.; Zevenbergen, C. How the failure to account for flexibility in the economic analysis of flood risk and coastal management strategies can result in maladaptive decisions. J. Waterw. Port Coast. Ocean Eng. 2012, 138, 386-393. [CrossRef]

35. Anvarifara, F.; Zevenbergen, C.; Thissen, W.; Islam, T. Understanding flexibility for multifunctional flood defences: A conceptual framework. J. Water Clim. Chang. 2016. [CrossRef]

36. Schulz, A.P.; Fricke, E.; Igenbergs, E. Enabling changes in systems throughout the entire life-cycle-Key to success? INCOSE Int. Symp. 2000, 10, 565-573.

37. Gersonius, B.; Ashley, R.; Pathirana, A.; Zevenbergen, C. Climate change uncertainty: Building flexibility into water and flood risk infrastructure. Clim. Chang. 2013, 116, 411-423. [CrossRef]

38. Zevenbergen, C.; Rijke, J.; van Herk, S.; Bloemen, P. Room for the river: A stepping stone in Adaptive Delta Management. Int. J. Water 2015, 3, 121-140.

39. Delta Commissaris. Delta Prgramme 2015: Working on the Dutch Delta in the 21st Century: A New Phase in the Battle against the Water; The Ministry of Infrastructure and Environment, The Ministry of Economic Afffairs: The Hague, The Netherlands, 2014.

40. Triantis, A.J. Real options. In Handbook of Modern Finance; RIA/Warren, Gorham \& Lamont: New York, NY, USA, 2003; pp. D1-D32.

41. Van Buuren, A.; Driessen, P.P.J.; van Rijswick, M.; Rietveld, P.; Salet, W.; Spit, T.; Teisman, G. Towards adaptive spatial planning for climate change: Balancing between robustness and flexibility. J. Eur. Environ. Plan. Law 2013, 10, 29-53. [CrossRef]

42. Woodward, M.; Kapelan, Z.; Gouldby, B. Adaptive flood risk management under climate change uncertainty using real options and optimization. Risk Anal. 2014, 34, 75-92. [CrossRef] [PubMed]

43. Haasnoot, M.; Middelkoop, H.; Offermans, A.; Beek, E.; van Deursen, W.P.A. Exploring pathways for sustainable water management in river deltas in a changing environment. Clim. Chang. 2012, 115, 795-819. [CrossRef]

44. Zhang, S.X.; Babovic, V. A real options approach to the design and architecture of water supply systems using innovative water technologies under uncertainty. J. Hydroinform. 2012, 14, 13-29. [CrossRef]

45. Felgenhauer, T.; Webster, M. Multiple adaptation types with mitigation: A framework for policy analysis. Glob. Environ. Chang. 2013, 23, 1556-1565. [CrossRef]

46. European Environment Agency. Urban Adaptation to Climate Change in Europe: Transforming Cities in a Changing Climate; European Environment Agency: Copenhagen, Denmark, 2016; p. 135.

47. Phi, H.L.; Hermans, L.M.; Douven, W.J.A.M.; Van Halsema, G.E.; Khan, M.F. A framework to assess plan implementation maturity with an application to flood management in Vietnam. Water Int. 2015, 40, 984-1003. [CrossRef]

48. Peters, G.B. The problem of policy problems. J. Comp. Policy Anal. Res. Pract. 2005, 7, 349-370. [CrossRef]

49. Ward, N.; Donaldson, A.; Lowe, P. Policy framing and learning the lessons from the UK's foot and mouth disease crisis. Environ. Plan. C Gov. Policy 2004, 22, 291-306. [CrossRef]

50. Infrastructure Victoria. All Things Considered; Infrastructure Victoria: Melbourne, Australia, 2016.

51. Satterthwaite, D. Adapting to Climate Change in Urban Areas: The Possibilities and Constraints in Low-and Middle-Income Nations; International Institute for Environment and Development: London, UK, 2007; Volume 1.

52. Rözer, V.; Müller, M.; Bubeck, P.; Kienzler, S.; Thieken, A.; Pech, I.; Schröter, K.; Buchholz, O.; Kreibich, H. Coping with pluvial floods by private households. Water 2016, 8, 304. [CrossRef]

53. Alberti, M.; Marzluff, J.M.; Shulenberger, E.; Bradley, G.; Ryan, C.; Zumbrunnen, C. Integrating humans into ecology: Opportunities and challenges for studying urban ecosystems. BioScience 2003, 53, 1169-1179. [CrossRef] 
54. De Sherbinin, A.; Schiller, A.; Pulsipher, A. The vulnerability of global cities to climate hazards. Environ. Urban. 2007, 19, 39-64. [CrossRef]

55. SCE. Can Tho (Vietnam): Comprehensive Resilience Planning For Integrated Flood Risk Mangement_Final Report; World Bank: Washington, DC, USA, 2013.

56. Bek, M.; Bugra, A.; Hjalmarsson, J.; Lista, A. Future Availability of Flood Insurance in UK: A Report on Legal Aspects of the Solutions Adopted in Australia, Iceland, The Netherlands, New Zealand and Turkey, with Conclusions; University of Southampton: Southampton, UK, 2013.

57. Revi, A.; Satterthwaite, D.E.; Aragón-Durand, F.; Corfee-Morlot, J.; Kiunsi, R.B.R.; Pelling, M.; Roberts, D.C.; Solecki, W. Urban areas. In Climate Change 2014: Impacts, Adaptation, and Vulnerability. Part A: Global and Sectoral Aspects. Contribution of Working Group II to the Fifth Assessment Report of the Intergovernmental Panel on Climate Change; Field, C.B., Barros, V.R., Dokken, D.J., Mach, K.J., Mastrandrea, M.D., Bilir, T.E., Chatterjee, M., Ebi, K.L., Estrada, Y.O., Genova, R.C., et al., Eds.; Cambridge University Press: Cambridge, UK; New York, NY, USA, 2014; pp. 535-612.

58. Quan, N.H.; Phi, H.L.; Tran, P.G.; Radhakrishnan, M.; Quang, C.N.X.; Thuyen, L.X.; Vinh, K.Q. Urban Retention Basin in Developing City: From Theoretical Effectiveness to Practical Feasibility. In Proceedings of the 13th International Conference on Urban Drainage, Kuching, Malaysia, 7-11 September 2014.

59. Serrao-Neumann, S.; Crick, F.; Harman, B.; Schuch, G.; Choy, D.L. Maximising synergies between disaster risk reduction and climate change adaptation: Potential enablers for improved planning outcomes. Environ. Sci. Policy 2015, 50, 46-61. [CrossRef]

60. Radhakrishnan, M.; Quan, N.H.; Gersonius, B.; Pathirana, A.; Vinh, K.Q.; Ashley, M.R.; Zevenbergen, C. Coping capacities for improving adaptation pathways for flood protection in Can Tho, Vietnam. Clim. Chang. 2017, under review.

61. Nilubon, P.; Veerbeek, W.; Zevenbergen, C. Amphibious architecture and design: A catalyst of opportunistic adaptation?-Case study Bangkok. Procedia Soc. Behav. Sci. 2016, 216, 470-480. [CrossRef]

62. United Nations Environment Programme. The Adaptation Gap Report 2014; United Nations Environment Programme (UNEP): Nairobi, Kenya, 2014; p. 68.

63. Intergovernmental Panel on Climate Change. Working Group I Contribution to the IPCC Fifth Assessment Report, Climate Change 2013: The Physical Science Basis, Summary for Policymakers; Intergovernmental Panel on Climate Change: Geneva, Switzerland, 2013.

64. Burkett, V.R.; Suarez, A.G.; Bindi, M.; Conde, C.; Mukerji, R.; Prather, M.J.; Clair, A.L.S.; Yohe, G.W. Point of departure. In Climate Change 2014: Impacts, Adaptation, and Vulnerability. Part A: Global and Sectoral Aspects. Contribution of Working Group II to the Fifth Assessment Report of the Intergovernmental Panel on Climate Change; Field, C.B., Barros, V.R., Dokken, D.J., Mach, K.J., Mastrandrea, M.D., Bilir, T.E., Chatterjee, M., Ebi, K.L., Estrada, Y.O., Genova, R.C., et al., Eds.; Cambridge University Press: Cambridge, UK; New York, NY, USA, 2014; pp. 169-194.

65. Pathirana, A.; Radhakrishnan, M.; Quan, N.H.; Zevenbergen, C. Managing urban water systems with significant adaptation deficits-Unified framework for secondary cities: Part I-Conceptual framework. Clim. Chang. 2017, under review.

66. Wolf, J. Climate change adaptation as a social process. In Climate Change Adaptation in Developed Nations: From Theory to Practice; Ford, D.J., Berrang-Ford, L., Eds.; Springer: Dordrecht, The Netherlands, 2011; pp. 21-32.

67. Storch, H.; Downes, N.K. A scenario-based approach to assess Ho Chi Minh City's urban development strategies against the impact of climate change. Cities 2011, 28, 517-526. [CrossRef]

68. Garschagen, M.; Romero-Lankao, P. Exploring the relationships between urbanization trends and climate change vulnerability. Clim. Chang. 2013, 133, 37-52. [CrossRef]

69. Samoli, E.; Atkinson, R.W.; Analitis, A.; Fuller, G.W.; Green, D.C.; Mudway, I.; Anderson, H.R.; Kelly, F.J. Associations of short-term exposure to traffic-related air pollution with cardiovascular and respiratory hospital admissions in London, UK. Occup. Environ. Med. 2016. [CrossRef] [PubMed]

70. Ashley, R. (Ed.) Interactions with Flood Affected People of Brisbane 2011 Floods; Richard Ashley: Brisbane, Australia, 2012.

71. Fletcher, T.D.; Shuster, W.; Hunt, W.F.; Ashley, R.; Butler, D.; Arthur, S.; Trowsdale, S.; Barraud, S.; Semadeni-Davies, A.; Bertrand-Krajewski, J.-L.; et al. SUDS, LID, BMPs, WSUD and more-The evolution and application of terminology surrounding urban drainage. Urban Water J. 2015, 12, 525-542. [CrossRef] 
72. Ashley, R.; Lundy, L.; Ward, S.; Shaffer, P.; Walker, L.; Morgan, C.; Saul, A.; Wong, T.; Moore, S. Water-sensitive urban design: Opportunities for the UK. Proc. Inst. Civ. Eng. Munic. Eng. 2013, 166, 65-76. [CrossRef]

73. Wesselink, A.; Warner, J.; Syed, M.A.; Chan, F.K.S.; Tran, D.D.; Huq, H.; Fredrik, H.; Ngan Le, T.; Nicholas, P.; Martijn, V.S. Trends in flood risk management in deltas around the world: Are we going 'soft'? Int. J. Water Gov. 2016, 3, 25-46. [CrossRef]

74. Lempert, R.J. Shaping the Next One Hundred Years: New Methods for Quantitative, Long-Term Policy Analysis; Rand Corporation: Santa Monica, CA, USA, 2003.

75. Mekong Delta Plan. Mekong Delta Plan-Long-Term Vision and Strategy for a Safe, Prosperous and Sustainable Delta; Ministry of Natural Rescources and Environment: Hanoi, Vietnam; Ministry of Agriculture and Rural Development: Hanoi, Vietnam; Ministry of Infrastructure and Environment: The Hague, The Nerthlands; Consortium of Royal HaskoningDHV: Amersfoort, The Nerthlands; Wageningen University and Research Centre: Wageningen, The Nerthlands; Deltares: Delft, The Nerthlands; Rebel: Amersfoot, The Nertherlands; Water.NL: Amersfoot, The Nertherlands, 2013.

76. Intergovernmental Panel on Climate Change. Climate Change 2014: Impacts, Adaptation, and Vulnerability. Part B: Regional Aspects. Contribution of Working Group II to the Fifth Assessment Report of the Intergovernmental Panel on Climate Change; Barros, V.R., Field, C.B., Dokken, D.J., Mastrandrea, M.D., Mach, K.J., Bilir, T.E., Chatterjee, M., Ebi, K.L., Estrada, Y.O., Genova, R.C., et al., Eds.; Cambridge University Press: Cambridge, UK; New York, NY, USA, 2014; p. 688.

77. Huong, H.; Pathirana, A. Urbanization and climate change impacts on future urban flood risk in Can Tho city, Vietnam. Hydrol. Earth Syst. Sci. Discuss. 2013, 17, 379-394. [CrossRef]

78. Van, P.; Van Griensven, A.; Solomatine, D.; Trung, N.; Green, A. A study of the climate change impacts on fluvial flood propagation in the Vietnamese Mekong Delta. Hydrol. Earth Syst. Sci. 2012, 16, 4637-4649. [CrossRef]

79. Wassmann, R.; Hien, N.; Hoanh, C.; Tuong, T. Sea level rise affecting the Vietnamese Mekong Delta: Water elevation in the flood season and implications for rice production. Clim. Chang. 2004, 66, 89-107. [CrossRef]

80. Smajgl, A.; Toan, T.Q.; Nhan, D.K.; Ward, J.; Trung, N.H.; Tri, L.Q.; Tri, V.P.D.; Vu, P.T. Responding to rising sea levels in the Mekong Delta. Nat. Clim. Chang. 2015, 5, 167-174. [CrossRef]

81. Garschagen, M. Risky Change? Vulnerability and Adaptation between Climate Change and Transformation Dynamics in Can Tho City, Vietnam; Megacities and Global Change; Steiner: Stuttgart, Germany, 2014; Volume 15.

82. World Bank. Can Tho, Vietnam enhancing urban resilience: Cities strength-Resilient cities program. In Global Practice on Social, Urban, Rural and Resilience; The World Bank Group: Washington, DC, USA, 2014.

83. Garschagen, M. Risky Change? Vietnam's urban flood risk governance between climate dynamics and transformation. Pac. Aff. 2015, 88, 599-621.

84. Radhakrishnan, M. Closing the gap between knowledge and practice. In Proceedings of the Green Designs for Integrated Urban Water Cycle Management-Solutions for Secondary Cities in Global South to Cope with Climate Change, Can Tho City, Vietnam, 8-10 December 2015. Available online: http:/ / mare-asia.net/ closing-the-gap-between-knowledge-and-practice/ (accessed on 12 February 2016).

85. Southern Sub-Institute of Urban and Rural Planning (VIAP-SIUP). Master Plan of Can Tho City until 2030 and Vision to 2050; Southern Sub-Institute of Urban and Rural Planning (VIAP-SIUP): Hanoi, Vietnam, 2013.

86. Birkmann, J.; Garschagen, M.; Kraas, F.; Quang, N. Adaptive urban governance: New challenges for the second generation of urban adaptation strategies to climate change. Sustain. Sci. 2010, 5, 185-206.

87. Development Workshop France. Survey on Perception of risk in Can Tho City; Chantry, G., Ed.; Development Workshop France: Lauzerte, France, 2011.

88. Clemens, M.; Rijke, J.; Pathirana, A.; Evers, J.; Hong Quan, N. Social learning for adaptation to climate change in developing countries: Insights from Vietnam. J. Water Clim. Chang. 2015. [CrossRef]

89. Southern Institute for Water Resources Planning (SIWRP). The Flood Protection Plan for Can Tho City; Southern Institute for Water Resources Planning (SIWRP): Ho Chi Minh City, Vietnam, 2011.

90. Chinh, D.T.; Gain, A.; Dung, N.; Haase, D.; Kreibich, H. Multi-variate analyses of flood loss in Can Tho City, Mekong Delta. Water 2016, 8, 6. [CrossRef]

91. Chinh, D.T.; Dung, N.V.; Kreibich, H.; Bubeck, P. The 2011 flood event in the Mekong Delta: Preparedness, response, damage and recovery of private households and small businesses. Disasters 2016, 40, 753-778. [CrossRef] [PubMed] 
92. Leimbach, M.; Kriegler, E.; Roming, N.; Schwanitz, J. Future growth patterns of world regions-A GDP scenario approach. Glob. Environ. Chang. 2015, 42, 215-225. [CrossRef]

93. Jiang, L.; O'Neill, B.C. Global urbanization projections for the Shared Socioeconomic Pathways. Glob. Environ. Chang. 2015, 42, 193-199. [CrossRef]

94. Prime Ministers Office. Decision 567, 568 Dated 14 September 2013 of the Prime Minister (PM) Approving Socio Economic Development Plan of Can Tho City till 2020 and Vision 2030; Prime Ministers Office: Hanoi, Vietnam, 2013.

95. O’Neill, B.C.; Kriegler, E.; Ebi, K.L.; Kemp-Benedict, E.; Riahi, K.; Rothman, D.S.; van Ruijven, B.J.; van Vuuren, D.P.; Birkmann, J.; Kok, K. The roads ahead: Narratives for shared socioeconomic pathways describing world futures in the 21st century. Glob. Environ. Chang. 2015, 42, 169-180. [CrossRef]

96. Haasnoot, M.; van Deursen, W.P.A.; Guillaume, J.H.A.; Kwakkel, J.H.; van Beek, E.; Middelkoop, H. Fit for purpose? Building and evaluating a fast, integrated model for exploring water policy pathways. Environ. Model. Softw. 2014, 60, 99-120.

97. Kwakkel, J.H.; Haasnoot, M.; Walker, W.E. Developing dynamic adaptive policy pathways: A computer-assisted approach for developing adaptive strategies for a deeply uncertain world. Clim. Chang. 2015, 132, 373-386. [CrossRef]

98. Central Research Institute for Dryland Agriculture. Water Resources Planning $\mathcal{E}$ Design for an Uncertain Future; Mendoza, G., John, M., Jeuken, A., Eds.; International Center for Integrated Water Resources Management: Alexandria, VA, USA, 2016.

99. Aerts, J.C.J.H.; Botzen, W.J.W.; Emanuel, K.; Lin, N.; de Moel, H.; Michel-Kerjan, E.O. Evaluating flood resilience strategies for coastal megacities. Science 2014, 344, 473-475. [CrossRef] [PubMed]

100. Buurman, J.; Babovic, V. Adaptation Pathways and Real Options Analysis: An approach to deep uncertainty in climate change adaptation policies. Policy Soc. 2016, 35, 137-150. [CrossRef]

101. Kasprzyk, J.R.; Reed, P.M.; Hadka, D.M. Battling arrow's paradox to discover robust water management alternatives. J. Water Resour. Plan. Manag. 2016, 142, 04015053. [CrossRef]

102. Wang, T. Real Options "in" Projects and Systems Design: Identification of Options and Solutions for Path Dependency; Massachusetts Institute of Technology: Cambridge, MA, USA, 2005.

103. Adger, W.N.; Pulhin, J.M.; Barnett, J.; Dabelko, G.D.; Hovelsrud, G.K.; Levy, M.; Oswald Spring, Ú.; Vogel, C.H. Human security. In Climate Change 2014: Impacts, Adaptation, and Vulnerability. Part A: Global and Sectoral Aspects. Contribution of Working Group II to the Fifth Assessment Report of the Intergovernmental Panel on Climate Change; Field, C.B., Barros, V.R., Dokken, D.J., Mach, K.J., Mastrandrea, M.D., Bilir, T.E., Chatterjee, M., Ebi, K.L., Estrada, Y.O., Genova, R.C., et al., Eds.; Cambridge University Press: Cambridge, UK; New York, NY, USA, 2014; pp. 755-791.

104. Van Mathijs, V.; Jasper, E.; van Arwin, B. (Eds.) Action Research for Climate Change Adaptation; Routledge: Abingdon-on-Thames, UK, 2014.

105. Ashley, R.M.; Blanskby, J.; Newman, R.; Gersonius, B.; Poole, A.; Lindley, G.; Smith, S.; Ogden, S.; Nowell, R. Learning and Action Alliances to build capacity for flood resilience. J. Flood Risk Manag. 2012, 5, 14-22. [CrossRef]

106. Thorne, C.R.; Evans, E.P.; Penning-Rowsell, E.C. Future Flooding and Coastal Erosion Risks; Thomas Telford: London, UK, 2007.

(c) 2017 by the authors. Licensee MDPI, Basel, Switzerland. This article is an open access article distributed under the terms and conditions of the Creative Commons by Attribution-NonCommercial (CC BY-NC) license (http:/ / creativecommons.org/licenses / by-nc/4.0/). 